\title{
Awareness and attitude to liberalized safe abortion services among female students in University and Colleges of Arba Minch Town, Ethiopia
}

\author{
Worku Animaw ${ }^{1, *}$, Binyam Bogale ${ }^{2}$ \\ ${ }^{1}$ College of Medicine and Health Science, Bahir Dar University; Po, Box 79, Bahir Dar, Ethiopia \\ ${ }^{2}$ College of Medicine and Health Science, Arba Minch University NechSar Campus Po, Box 21, Arba Minch, Ethiopia
}

\section{Email address:}

workimaw@gmail.com (W. Animaw),binyadad@gmail.com (B. Bogale)

\section{To cite this article:}

Worku Animaw, Binyam Bogale. Awareness and Attitude to Liberalized Safe Abortion Services among Female Students in University and Colleges of Arba Minch Town, Ethiopia. Science Journal of Public Health. Vol. 2, No. 5, 2014, pp. 440-446.

doi: $10.11648 /$ j.sjph.20140205.20

\begin{abstract}
Background: Unsafe abortion is a significant cause of maternal mortality and morbidity globally. In 2005, the Ethiopian penal code was amended to permit abortion under specific circumstances to minimize the problem. However, its practice is hampered by lack of awareness of the revised criminal code and access to the service. Methods: Institution based cross-sectional qualitative and quantitative study has been conducted to assess awareness and attitude of university and college female students' to the law. A sample of 845 students from one university and three colleges of Arba Minch town were selected by multistage sampling method. Data entry, cleaning and coding were performed using SPSS version 16 and analyzed with the same soft ware. Associations between dependent and independent variables were tested using logistic regression. P-values $>0.05$ were considered to be statistically significant in all cases. Result: Twenty three (43\%) among 54 pregnancies were reported as ended with induced abortion. Ethiopia's abortion law was expected to increase women's access to safe abortion services but only 261 (32.1\%) of college and university students of Arba Minch town were aware about this law after 6 years of liberalization. Better level of awareness had been recorded in health science students as compared with natural science students $(\mathrm{OR}(95 \% \mathrm{CI})=2.8(1.9,4.2)$. Only $246(30.3 \%)$ among all participants $(813)$ were found to have positive attitude towards criteria set to induce abortion. This is roughly in line with health professionals' attitude at the time safe abortion service was on the process of liberalization. Conclusion: Religion, college (specialty) and sexual experience of students found to be the factors affecting attitude. The knowledge gap may let the students continually suffer from unsafe abortion sequel; so stakeholders should work on awareness creation.
\end{abstract}

Keywords: Awareness, Attitude, Inducing Abortion Law, Ethiopia, Female Students

\section{Introduction}

Many reports agreed that about quarter of all pregnancies worldwide end in an induced abortion; significant numbers of these are unsafe ${ }^{1,2}$. Unsafe abortion is a significant cause of maternal mortality and morbidity in the world. Globally, unsafe abortions claim the lives of 68,000 women each year; $43 \%$ of these women are African. Unsafe abortion remains a leading cause of maternal mortality and morbidity in Africa, accounting for an estimated $14 \%$ of maternal deaths ${ }^{3-5}$.

Until 2005 the Ethiopian penal code permitted abortion only to save the pregnant woman's life, but in 2005 the penal code was amended to permit abortion under a much broader set of circumstances; in the case of rape, incest or fetal impairment; if pregnancy continuation or birth would endanger the health or life of the woman or fetus; if the woman has physical or mental disabilities; and if the woman is a minor who is physically or mentally unprepared for childbirth. In most cases, a woman's statement is sufficient to establish the legal indication for, and allow her to obtain, the abortion but many Ethiopian women remain confused or unsure of their rights and don't know how to prevent unplanned pregnancies ${ }^{6-8}$. 
The Ethiopian government has accomplished a great deal since adopting the revised penal code. However, despite the progress, Ethiopian women continue to be confronted by obstacles to seeking abortion care. In 2005, Ethiopia's maternal mortality ratio was 720 deaths per 100,000 live births; however, maternal mortality in the country is still 676 per 100,000 live births notwithstanding the law ${ }^{9,10}$.

Study in India about the awareness of legal and safe abortion found that nearly 40 years after India legalized abortion; women continue to be unaware. This study shows that policy alone will only have a limited effect on the health and lives of women ${ }^{11}$. A study in Nepal about nine months after the abortion legislation showed that only $15 \%$ of the 1,100 rural married women of reproductive age interviewed were aware of the new abortion law, and 56 percent still believed that abortion was illegal in the country ${ }^{12}$.

Ethiopian Federal Ministry of Health in its Health sector development plan (HSDP) had planned to reduce unsafe abortion from $50 \%$ in 2005 to $10 \%$ in 2010 , however unsafe abortion is still above 50\%. A 2010 research and fieldwork in Ethiopia found that unsafe abortion causes more than half of the 20,000 maternal deaths that occur annually ${ }^{9,11}$. The reasons suggested are women and health care providers are not aware about the revised 2005 Criminal Code of the Federal Democratic Republic of Ethiopia ${ }^{14,15}$.

In 2008, 101 unintended pregnancies occurred per 1,000 women aged $15-44$, and $42 \%$ of all pregnancies were unintended. In 2008, an estimated 382,500 induced abortions were performed in Ethiopia, for an annual rate of 23 abortions per 1,000 women aged 15-44 and only $27 \%$ were safe. The main reasons for induced abortion were fear of the family and the community $31.3 \%$, not to interrupt school $26.6 \%$ and financial problem $14.1 \%{ }^{3,16}$.

A study conducted on health professionals in Ethiopia found that nearly quarter $(23.3 \%)$ health workers with incorrect abortion law knowledge provided legal abortion service. One study was conducted in Mekele to assess reproductive aged individuals' attitude to legalization safe abortion before it was liberalized in Ethiopia in 2002. This study found that out of the total respondents, 473 (56.4\%) preferred induced abortion on demand to be legalized, while 355 (42.4\%) opposed it ${ }^{17,18}$.

The transition from unsafe to safe abortions demands changes at national policy level; abortion training for service providers and the provision of services at the appropriate primary level health service delivery points; and ensuring that women access these services instead of those of untrained providers. Public awareness that abortion services are available is a crucial element of this transition, particularly among adolescent and single women, who tend to have less access to reproductive health services generally 2, 11. This study has aimed to assess the attitude and awareness of university and college female students' of Arba Minch town to legalized safe abortion and identifies factors affecting their awareness and attitude in March 2011.

\section{Methods}

Institution based cross-sectional qualitative and quantitative study has been conducted in March 2011 in Arba Minch town, Southern Ethiopia which is located about 500 kilometers south of Addis Ababa Capital city of Ethiopia ${ }^{19}$. Among nine colleges and one university in Arba Minch town, Arba Minch University and 3 colleges were randomly selected.

The sample size was determined by single population proportion formula with assumptions of expected proportion of awareness or attitude to legal abortion service in higher education institution students of Ethiopia was not known therefore $50 \%$, desired precision of $5 \%, 95 \%$ confidence level, 10\% none -response rate and design effect of two were considered. With this assumptions sample of 845 female students from selected institutions were involved in the study. These samples were allocated to each education institution, then to years stayed in that institution and then to the faculties (departments) students were learning proportional to number female students and at last each participants were selected by simple random sampling using their name list. Focus group discussions (FGD) comprising 8-12 students were conducted in each institution until saturation of idea was reached using interview guide. Focus group discussants were students selected randomly from different departments and sections in that particular college.

Ethical clearance was obtained from the Arba Minch University. Signed permission of the each participant was sought. To ensure data quality, pre-test was done in Arba Minch Health Science College which was not included in the study. Training was given for both data collectors and supervisors by the principal investigators. After intensive revision of literature, the final adopted English version was translated in to Amharic and back to English to assure consistency.

Data entry, data cleaning and coding were performed using SPSS version 16 and analyzed with the same soft ware. Students were considered as aware to abortion law if she answered half or more questions asking about criteria liberalized abortion correctly, unless were considered as not aware (not knowledgeable). Students were considered having positive attitude if her responses to attitude variables mean value was 2.5 or less in 5 scaled Likert scale questionnaire which were scaled from positive to negative unless considered as having negative attitude.

Associations between dependent and independent variables were assessed and presented using logistic regression using crude and adjusted odds ratio at $95 \%$ confidence interval (CI). Only those variables showed statistical significant $(\mathrm{p}<0.05)$ associations in crude odds ratio calculation (COR) are included in the consecutive adjusted logistics calculation (AOR). P-values $<0.05$ were considered to be statistically significant in all cases. FGD data were transcribed from audio cassette and triangulated with quantitative results. 


\section{Result}

All distributed questionnaires (845) were filled and returned but 32 questionnaires found to be incomplete and rejected from the analysis; giving response rate of $96.2 \%$. The study participants' median age was 20 years. Two hundred and sixty six (32.7\%) of the study participants were first year students and 319 students were stayed three years and above in the institution at the time of data collection.
Almost half of the study participants reported they did not know most of the criteria set by Ethiopian legislation which liberalized to induce abortion safely; $50.6 \%$ for physical disability and $48.2 \%$ for minors. Majority of the participants $(57.2 \%)$ knew there were criteria that safe abortion was liberalized in Ethiopian the rest $37.9 \%$ did not know and $10.5 \%$ reported there was no means that abortion could be carried out legally in Ethiopia. (Table 1)

Table 1. Knowledge of HEI students in Arba Minch town about criteria's of liberalized safe abortion services in Ethiopia, March, 2011 (N = 813).

\begin{tabular}{|c|c|c|c|c|c|c|}
\hline \multirow{3}{*}{ Variable } & \multicolumn{6}{|c|}{ Participants response to knowledge questions } \\
\hline & \multicolumn{2}{|c|}{ Yes } & \multicolumn{2}{|c|}{ No } & \multicolumn{2}{|c|}{ I do not know } \\
\hline & Freq & $\%$ & Freq & $\%$ & Freq & $\%$ \\
\hline Abortion is fully legalized by law in Ethiopia & 89 & 10.9 & 416 & 51.2 & 308 & 37.9 \\
\hline $\begin{array}{l}\text { There are some conditions that abortion is allowed by law in } \\
\text { Ethiopia }\end{array}$ & 465 & 57.2 & 85 & 10.5 & 262 & 32.2 \\
\hline $\begin{array}{l}\text { Safe abortion is allowed by law in Ethiopia if pregnancy is } \\
\text { resulted from rape. }\end{array}$ & 249 & 30.6 & 221 & 27.2 & 343 & 42.2 \\
\hline $\begin{array}{l}\text { Safe abortion is allowed by law in Ethiopia if pregnancy is } \\
\text { resulted from incest }\end{array}$ & 194 & 23.9 & 229 & 28.2 & 390 & 48.0 \\
\hline $\begin{array}{l}\text { Safe abortion allowed by law in Ethiopia if pregnancy causes } \\
\text { danger for the health or life of the woman. }\end{array}$ & 329 & 40.5 & 135 & 16.6 & 349 & 42.9 \\
\hline $\begin{array}{l}\text { Safe abortion allowed by law in Ethiopia if health or life of the } \\
\text { fetus is in danger. }\end{array}$ & 321 & 39.5 & 136 & 16.7 & 356 & 43.8 \\
\hline $\begin{array}{l}\text { Safe abortion is allowed by law in Ethiopia in cases of fetal } \\
\text { abnormalities }\end{array}$ & 270 & 33.2 & 156 & 19.2 & 387 & 47.6 \\
\hline $\begin{array}{l}\text { Abortion is allowed by law in Ethiopia for women with physical } \\
\text { disabilities. }\end{array}$ & 136 & 16.7 & 266 & 32.7 & 411 & 50.6 \\
\hline $\begin{array}{l}\text { Abortion is allowed by law in Ethiopia for women with mental } \\
\text { disabilities. }\end{array}$ & 189 & 23.2 & 230 & 28.3 & 394 & 48.5 \\
\hline $\begin{array}{l}\text { Abortion is allowed by law in Ethiopia for minors who are } \\
\text { physically or psychologically unprepared to raise a child }\end{array}$ & 203 & 25.0 & 218 & 26.8 & 392 & 48.2 \\
\hline
\end{tabular}

Study participants were asked questions asking their knowledge about criteria set by the law which liberalized safe abortion service. Those questions were counted as shown in the figure below. Only sixteen students among 813 participants $(1.9 \%)$ knew all the criteria asked about abortion law which liberalized safe abortion service. Majority of the students knew only one criterion (173(21.28\%). Ninety four students $(11.5 \%)$ were totally unaware of the criteria set by law. (Figure 1)

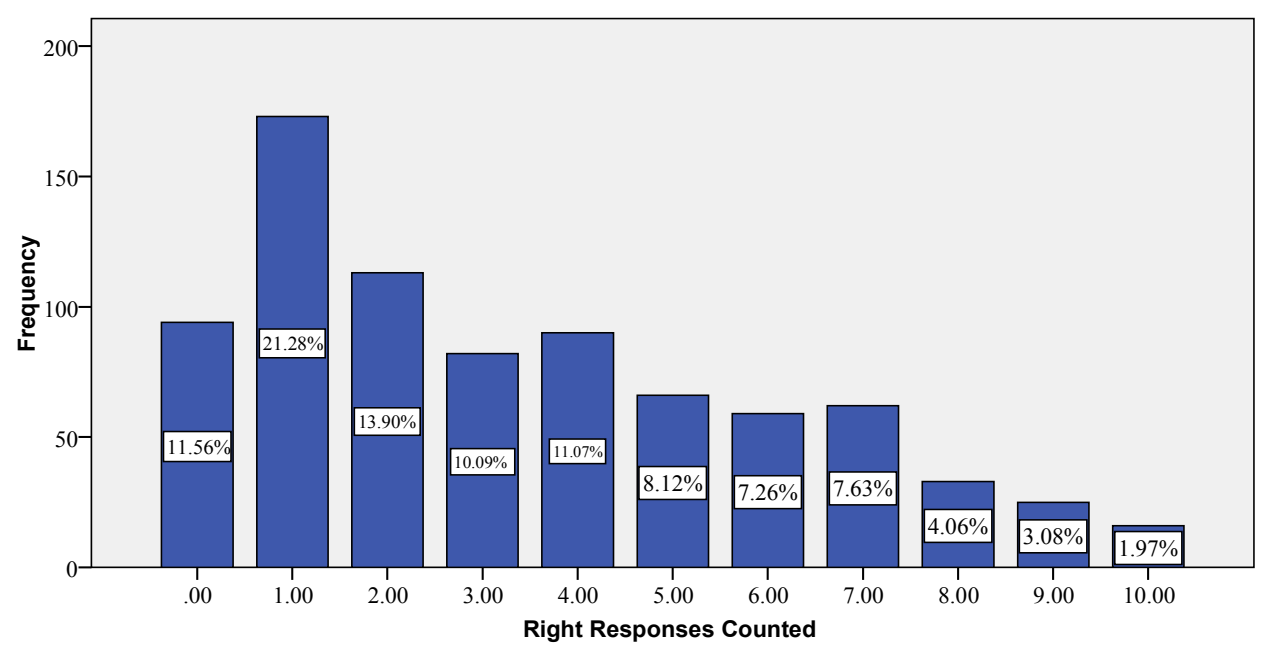

Fig 1. Knowledge to Ethiopian Liberalization Criteria to induce abortion among students in Arba Minch town HEI, 2011 (N = 813).

Generally 552(67.9\%) of the total 813 study participants were found to be not knowledgeable about the law that liberalized induce abortion. Statistical significant knowledge difference was not seen between students living in or out of campus and whether they had or not husband/boyfriend.

Years students stayed in campus were found not to affect their knowledge to the law that liberalized induce abortion 
in Ethiopia COR $(95 \% \mathrm{CI})$ of year two, three were 1.1(0.7, 1.6) and $1.0(0.7,1.4)$ as compared with year one. Similar proportion (two third) of students from each year were not knowledgeable to the law. (Table 2)

Eighty two (52.9\%) of health science and medical students were knowledgeable about the criteria set to liberalized inducing abortion safely in Ethiopian as compared with students from natural science, social science and education 92(28.2\%), 51(26.2\%) and 36(26.3\%) respectively. The COR $(95 \% \mathrm{CI})$ of health science and medical students were $2.8(1.9,4.2)$ as compared with natural science students. The odds ratios of students from social science and education showed no significant statistical knowledge difference to abortion law with natural science students. (Table 2)

Table 2. Factors contributing to knowledge about Ethiopian Liberalization Criteria to induce abortion among students in Arba Minch town HEI, 2011 (N $=813)$.

\begin{tabular}{|c|c|c|c|c|}
\hline \multirow{2}{*}{ Variable } & \multirow{2}{*}{ Category } & \multicolumn{2}{|l|}{ Knowledge to Abortion Law } & \multirow{2}{*}{ OR $(95 \% \mathrm{CI})$} \\
\hline & & Not Knowledgeable Freq (\%) & Knowledgeable Freq (\%) & \\
\hline \multirow{5}{*}{ Religion } & Orthodox & $321(66.5)$ & $162(33.5)$ & 1 \\
\hline & Muslim & $53(66.2)$ & $27(33.8)$ & $1.0(0.6,1.6$ \\
\hline & Protestant & $150(67.9)$ & $71(32.1)$ & $0.9(0.6,1.3)$ \\
\hline & Catholic & 5 & -- & -- \\
\hline & Other & 23 & 1 & $0.0(0.1,0.6)$ \\
\hline \multirow{3}{*}{ Years in HEI } & One & $183(68.8)$ & $83(31.2)$ & 1 \\
\hline & Two & $151(66.2)$ & $77(33.8)$ & $1.1(0.7,1.6)$ \\
\hline & Three & $218(68.3)$ & $101(31.7)$ & $1.0(0.7,1.4)$ \\
\hline \multirow{4}{*}{ College/faculty } & Natural Science & $234(71.8)$ & $92(28.2)$ & 1 \\
\hline & Health Science & $73(47.1)$ & $82(52.9)$ & $2.8(1.9,4.2)^{*}$ \\
\hline & Social Science & $144(73.8)$ & $51(26.2)$ & $0.9(0.6,1.3)$ \\
\hline & Education & $101(73.7)$ & $36(26.3)$ & $0.9(0.5,1.4)$ \\
\hline \multirow{2}{*}{ Current Residence } & In campus & $371(67.3)$ & 18032.7) & 1 \\
\hline & Out of Campus & $181(69.1)$ & $81(30.9)$ & $0.9(0.6,1.2)$ \\
\hline \multirow{2}{*}{ Have husband/boy friend } & Yes & $240(66.3)$ & $122(33.7$ & 1 \\
\hline & No & $312(69.2)$ & $139(30.8)$ & $0.8(0.6,1.1)$ \\
\hline
\end{tabular}

*: the only variable show statistical significant difference, hence no other variables detected here to be adjusted (calculating (AOR)) with.

Focus group discussion result also revealed significant knowledge gap; a second year secretarial science student from rural part of the Gamo Gofa Zone said "our government does not allow inducing abortion in any situations, it is killing human life and murder is punishable and I do not believe our government will legalize abortion at any means ever". Her friend from similar background agreed with all points and added "of course I know women inducing abortion in different places and mechanisms but they are criminal for doing that and sinful for interrupting nature and God's will". In contrast in other FGD session a third year nursing student from Arbaminch University described almost all criteria liberalized inducing abortion and added "the girl even will not be asked to bring any evidence that she has been raped; only her verbal report is enough to terminated her pregnancy safely and legally."

Focus group discussants in their discussion sessions mentioned the mechanisms abortion is traditionally induced. Almost all discussants mentioned Coca-Cola with many tablets given for headache (Paracetamol) is mostly used to induce abortion. Many others agreed drinking water boiled with grinded Khat (stimulant vegetable commonly used as social recreation in Eastern Africa) is usually effective to evacuate the new conception. These two mechanisms are used to induce abortion by the woman herself at her home. Discussants also mentioned what traditional abortionists use to induce abortion. A students from private college said
"I know a man who inject black fluid (tar of fuel lamp diluted in water) on navel and he urged the girl to go to her home before she starts bleeding and faints in his home". Her friend added that "these traditional abortionists insert glucose tube (IV tube) into her uterus, let it open air to inter and then blood starts to leak out." Many discussants knew different complications of abortion. They mentioned bleeding, infection, fistula, infertility and even death may occur.

Study participants' attitude to law and its criteria liberalized safe abortion service was also assessed. Though about half of study students believed safe abortion service should be legalized for everyone in need of the service, majority of them strongly agreed that abortion is unacceptable by their religion and by their community; $75.3 \%$ and $60.5 \%$ respectively. (Table 3 )

Five hundred and sixty seven (69.7\%) study participants had negative attitude towards the law to liberalize inducing abortion in Ethiopia. About one third of students who had husband or boy friend found to have positive attitude towards the law liberalizing abortion as compared with $26.6 \%$ who had no husband or boyfriend. (Table 3 )

Seventy $(45.2 \%)$ of students from health science faculty (specialty) found to have positive attitude where as students having positive attitude from natural science, social science and education were 96(29.4\%), 58(29.7) and $22(16.1 \%)$ respectively. The AOR $(95 \% \mathrm{CI})$ of students 
from health science, social science and education are $0.4(0.3,0.7), 0.9(0.6,1.4)$ and $1.8(1.1,3.1)$ respectively as compared with students from natural science. (Table 3 )

More than half $(57.2 \%)$ of students among never had sexual intercourse had negative attitude to abortion law as compared with $73.1 \%$ students ever had sexual intercourse; AOR (95\% CI) 1.8(1.2, 2.7). (Table 3)

Table 3. Attitude to law liberalized inducing abortion in Ethiopia among students in Arba Minch Town Higher Education Institutions (HEI) 2011 (N = 813)

\begin{tabular}{|c|c|c|c|c|c|}
\hline \multirow{2}{*}{ Variable } & \multirow{2}{*}{ Category } & \multicolumn{2}{|c|}{ Attitude to Liberalization of Abortion } & \multirow{2}{*}{ COR $(95 \%$ CI) } & \multirow{2}{*}{$\operatorname{AOR}(95 \% \mathrm{CI})$} \\
\hline & & Positive F(\%) & Negative $\mathbf{F}(\%)$ & & \\
\hline \multirow{5}{*}{$\begin{array}{l}\text { Income perception Relative } \\
\text { to friends }\end{array}$} & Very good & $22(34.9)$ & $41(65.1)$ & 1 & \\
\hline & Good & $38(31.70$ & $82(68.3)$ & $1.1(0.6,2.2)$ & \\
\hline & Similar & $141(27.5)$ & $371(72.5)$ & $1.4(0.8,2.4)$ & \\
\hline & Low & $27(32.9)$ & $55(67.1)$ & $1.0(0.5,2.1)$ & \\
\hline & Too low & $18(50.0)$ & $18(50.0)$ & $0.5(0.2,1.2)$ & \\
\hline \multirow{4}{*}{ College (Specialty) } & Natural Science & $96(29.4)$ & $230(70.0)$ & 1 & 1 \\
\hline & Health Science & $70(45.2)$ & $85(54.80$ & $0.5(0.3,0.7)$ & $0.4(0.3,0.7)$ \\
\hline & Social Science & $58(29.70$ & $137(70.3)$ & $0.9(0.6,1.4)$ & $0.9(0.6,1.4)$ \\
\hline & Education & $22(16.1)$ & $115(83.9)$ & $2.1(1.3,3.6)$ & $1.8(1.1,3.1)^{*}$ \\
\hline \multirow{3}{*}{ Years Stayed in HEI } & One & $77(28.9)$ & $189(71.1)$ & 1 & \\
\hline & Two & $82(36.0)$ & $146(64.0)$ & $0.7(0.4,1.0)$ & \\
\hline & Three and Above & $87(27.3)$ & $232(72.7)$ & $1.0(0.7,1.5)$ & \\
\hline \multirow{2}{*}{ Current Residence } & In campus & $174(31.6)$ & $377(68.4)$ & 1 & \\
\hline & Out of Campus & $72(27.5)$ & $190(72.5)$ & $1.2(0.8,1.6)$ & \\
\hline \multirow{5}{*}{ Religion } & Orthodox & $163(33.7)$ & $320(66.3)$ & 1 & 1 \\
\hline & Muslim & $23(28.8)$ & $57(71.2)$ & $1.2(0.7,2.1)$ & $1.1(0.6,1.9)$ \\
\hline & Protestant & $49(22.2)$ & $172(77.8)$ & $1.7(1.2,2.5)$ & $1.6(1.1,2.3)^{*}$ \\
\hline & Catholic & $2(40.0)$ & $3(60.0)$ & $0.7(0.1,4.6)$ & $0.7(0.1,4.5)$ \\
\hline & Other & $9(37.0)$ & $15(62.5)$ & $0.8(0.3,1.9)$ & $0.7(0.3,1.9)$ \\
\hline \multirow{2}{*}{ Ever had sexual intercourse } & Yes & $74(42.8)$ & $99(57.2)$ & 1 & 1 \\
\hline & No & $172(26.9)$ & $468(73.1)$ & $2.0(1.4,2.8)$ & $1.8(1 \cdot 2,2.7)^{*}$ \\
\hline \multirow{2}{*}{ Have husband/boy friend } & Yes & $126(34.8)$ & $236(65.2)$ & 1 & 1 \\
\hline & No & $120(26.6)$ & $331(73.4)$ & $1.4(1.0,1.9)$ & $1.1(0.8,1.6)$ \\
\hline
\end{tabular}

*: variables maintain their statistical significance after being adjusted with other variables

FGD discussants were also at two different poles on their attitude about inducing abortion. A fourth year health science students said "It is my right to decide on my life, it is my right to decide when to have a baby. There are different occasions I can get pregnant and I will never ever allow the new creature to ruin my life". Other student from other college said "Imagine, If I get rapped and I became pregnant 'do you think I am going to bear this bastards' child?' No. Even if I deliver the child safely I will throw it; at any time I see the child I always remember the moment I get raped and I may become useless and crazy. Therefore, whether legally or illegally, safely or dangerously I will try all I can do to remove this dirt from my uterus even if I may die". Many discussants on the side of this idea recommended the country (Ethiopia) to fully legalize abortion for any one in need of inducing abortion without any preconditions.

Discussants stand in the other side argued with their justifications why they object the law liberalized abortion. A second year student from Arba Minch University mentioned that "we all know cell has life; and fetus is beyond that, so we must not kill a life". Other student from social study stream supported her idea "everybody has his own destiny if I become pregnant accidentally that is my destiny and the new creature has its own destiny so nobody should interfere with one's fate." Almost all of students in this pole majorly focused on religious issues. Many of the discussants in this side object abortion to be legalized unless it endangers the life of the mother.

\section{Discussion}

Even though Ethiopia liberalized safe abortion service for those fulfilling the criteria set by legislation since 2006, only a third of higher education institutions' (HEIs) students of Arba Minch town were aware about these criteria after 6 years of liberalization ${ }^{8}$.

Only few Ethiopian girls get access to learn in higher education programs. This smaller proportion of female population of the country are better educated and expected to be more aware about reproductive health $(\mathrm{RH})$ policies of the country. Almost two third of this population (HEI students) found to be unaware about abortion induction law of the country after six years of its liberalization. The investigators of this study believe that the awareness level might be worse in the general population of the country. Significant proportion of female populations from the general population of India and Nepal were found to be not aware about abortion law after decades safe abortion service was legalized in the countries; where there might be no difference in Ethiopian general female populations. ${ }^{11,12}$

In the bivariate logistics regression test only one variable showed statistical association with students' knowledge to abortion law; hence adjustment (AOR) was not indicated thus adjusted odds ratio (AOR) calculation did not operated. The only identified factor contributing to students' 
knowledge to abortion law was the specialty they were attending. Knowledge of students from health science faculty to abortion law were nearly threefold as compared to students from natural science faculty (OR 95\% (CI) $=$ $2.8(1.9,4.2))$. The reason for this knowledge difference between students from health science and other colleges could be; the curriculum of health science incorporates different reproductive health policies including abortion law, the burden of abortion in national and global level and clinical guidelines of safe abortion induction. Students from other specialties could not have such exposure to issues related with abortion.

Before Ethiopia liberalized abortion with criteria community based study in Mekele in 2002 found that more than half of the study participants preferred induced abortion to be legalized on demand. After 12 years of this study (study in Mekele) and after 6 years abortion was liberalized, almost half of the higher education institutions' (HEIs) students preferred safe abortion service to be legalized for everyone in need of the service ${ }^{18}$.

Though about half of study students believed safe abortion service should be legalized for everyone in need of abortion service, majority of them perceived that abortion is unacceptable by their religion and community. This finding is compatible with the community based study conducted in Nepal in $2009^{12}$. (Table 3)

Majority of study participants had negative attitude towards the criteria set to liberalized inducing abortion in Ethiopia. Similarly more than half of health professionals also had negative attitude towards inducing abortion at the time safe abortion service was on the process of liberalization. These negative attitudes by both service providers and consumers will have significant impact on safe abortion service as women in need of abortion service may prefer illegal providers who could treat them privately; which hampers reducing unsafe abortion practices and its sequel ${ }^{17}$

The specialty students were attending maintains its significant impact on their attitude too. The odds of students from health science were 1.4 times to have positive attitude as compared with students from natural science. Students from education were 1.8 times more likely to have negative attitude than students from natural science. Even though no related literatures could be accessed to discuss on, the justifications given on knowledge difference could also work here on the attitude part. The courses health science students had taken may significantly affect their attitude. They have been taught the magnitude and severity of abortion consequences; they also knew these sequels are due to unsafe induction of abortion which could be avoided or significantly reduced by providing safe abortion service granted by law. In reverse most courses in social science teaches moral issues, cultural and religious norms; have no contents to discuss on the burden of unsafe abortion.

Another identified independent factor affecting the attitude of students was students' sexual experience. As students get involved sexual activities they became receptive to inducing abortion. This could be due to; as they get involved sexual activities they understood they are at risk of unplanned pregnancy and even get pregnant, then they seek for abortion service and they understood its advantage; hence became receptive to safe and legal abortion service.

The dialogue on legality of abortion is always hot issue in the world. FGD discussants were also at two different poles on their attitude about inducing abortion. Surprisingly discussants at each education institutions were having two opposing attitude; one team was in favor of inducing abortion is acceptable and mandatory and other were against this group ${ }^{20}$.

Various studies indicated that policy alone will not play significant role in improving reproductive health of a women. Notwithstanding the new law, almost six in 10 abortions in Ethiopia were unsafe. This may be due to they were not aware about the law. The current study revealed awareness gape about abortion law is significant and Ethiopian women may continue suffering with sequels of unwanted pregnancy and unsafe abortion 5, 7,11.

Ethiopia's abortion law was expected to increase women's access to safe abortion services and reduce maternal mortality and morbidity due to unsafe abortion. Reports indicated university and college students are the most vulnerable group to sexual and reproductive health problems mainly abortion related problems. However, majority of university and college students of study area were not aware about the law and hence susceptible to unsafe abortion ${ }^{7,13}$.

Though this legislation (legislation liberalized inducing abortion) is saving lots of life, it is not attaining its ultimate goal. Even though FGD discussants were reluctant to disclose their own experiences, they mentioned experiences of their friends, abortion is induced using different traditional means most of the mechanisms endangered the health and life of the women. Most discussants agreed abortion is common in their community significant of it were unsafe causing death and major health problems. Low public to awareness abortion and abortion law could partly contributed unsafe abortion practices with other possible reasons which are beyond the scope this particular study.

\section{Conclusions}

After six years abortion was liberalized with selected criteria, majority of college and university students of Arba Minch town were not aware about the law. Health science and medical students were more aware as compared with students from other colleges. About two third of the students found to have negative attitude to the law liberalized safe abortion service. Students' sexual experience, college/specialty they were learning and religion were the factors affecting their attitude. As students experienced sex they became receptive to abortion induction. 
Governmental and none governmental organizations, clubs and any other parties working of reproductive health shall create better awareness on abortion law to reduce maternal morbidity and mortality due to unsafe abortion; some contents about reproductive health policies focusing on abortion could be taken from health science courses and make others familiarize with it.

\section{Acknowledgement}

We would like to acknowledge Arba Minch University College of Medicine and Health Science for funding this stud. In addition, we would like to thank data collectors and study participants.

\section{Competing Interest}

We declare that we have no any competing interest.

\section{Authors' Contribution}

Worku A. has involved in the conception, design, analysis, data interpretation and report writing. Biniyan B. has involved in the design, analysis and report writing.

\section{References}

[1] World Health Organization (WHO), Unsafe Abortion: Global and Regional Estimates of the Incidence of Unsafe Abortion and Associated Mortality in 2003, fifth ed., Geneva: WHO, 2007.

[2] Berer M. Making abortions safe: a matter of good public health policy and practice, Geneva , Bull World Health Organ, 2000, 78(5).

[3] Elias S., Getu Degu A., Nuru A., Hailu Y. Prevalence and associated risk factors of Induced Abortion in northwest Ethiopia, Ethiop.J.Health Dev. 2005;19(1):37-44.

[4] Kebede Y. Contraceptive prevalence and factors associated with usage of contraceptive around Gondar town. Ethiop. J. Health Dev. 2000; 14(13): 327-34.

[5] Pathfinder International Ethiopia: Feature Stories. "Youth in Need of Services in Ethiopia: Pathfinder Working to Ensure Needs Are Met.” Apr. 2008.

[6] Singh S, Fetters T, Gebreselassie H, Abdella A, Gebrehiwot Y, Kumbi S and Audam S, The estimated incidence of induced abortion in Ethiopia, International Perspectives on Sexual and Reproductive Health, 2010, 36(1):16-25.
[7] Hailemichael G, Tamara F, Susheela S, Caring for Women with Abortion Complications in Ethiopia: National Estimates and Future Implications, Addis Ababa, Ethiopia, International Perspectives on Sexual and Reproductive Health 2010, 36(1): 6-15

[8] Federal Democratic Republic Ethiopia, The Criminal Code of the Federal Democratic Republic of Ethiopia, Proclamation Number 414/2004, Article, 551, 2004.

[9] Neesha G., Anna S. and Rachel V. Bridging the Gaps: Implementation of Comprehensive Abortion Care in Ethiopia, Addis Ababa, Ethiopia, 2008.

[10] Central Statistical Agency. Ethiopia demographic and health survey 2011, Addis Ababa, Ethiopia, 2012.

[11] Ojha N, Sharma S. and Paudel J. Post legalization challenge: minimizing complications of abortion, Nepal, Kathmandu University Medical Journal (2003) 2(2), Issue 6, 131-136.

[12] Anand T., Ramesh A., and Shekhar D. Increasing Awareness and Access to Safe Abortion Among Nepalese Women.Center for Research on Environment. Downloaded from, www.crehpa.org.np. Accessed on September 2010.

[13] IPAS Ethiopia, Abortion in Ethiopia - Fast Facts, Downloaded for www.NotYetRain.org. Accessed on September 2010.

[14] World Health Organization (WHO), Unsafe Abortion: Global and Regional Estimates of the Incidence of Unsafe Abortion and Associated Mortality in 2003, fifth ed., Geneva: WHO, 2007.

[15] Federal Ministry of Health of Ethiopia. 2005. Health sector strategic plan (HSDP-III) 2005/6-2009/10. Government of Ethiopia, Addis Ababa

[16] Yirgu G., Solomon T., Takele G. et al. Caring for Women with Abortion Complications in Ethiopia. International Perspectives on Sexual and Reproductive Health. 2009; 36(1):20 - 45 .

[17] Ethiopian Society of Obstetrician and Gynecologists. KAP study on abortion among Ethiopian health workers. BSSP. 2002 .

[18] Abay, H. Assessment of the attitude of 15 - 49 year old women and men towards legalization of abortion in Mekele town, Tigray, Ethiopia. Addis Ababa, Ethiopia: Addis Ababa Univesity; 2002.

[19] Central Statistical Agency. Summary and Statistical Report of Population and Housing Census Results. Addis Ababa: United Nations Population Fund (UNFPA); December 2008.

[20] Sara J., Michelle B. etal. A detailed Summary of Anti Abortion Research Paper. NYC, USA, 2010. 